\title{
A rare cause of acute abdomen in a young female patient
}

\author{
N. Matsumoto ${ }^{1,2}$, H. Fujikawa ${ }^{1,3}$, S. Nishioka ${ }^{1}$, S. Yamashita ${ }^{2}$, T. Yoshizawa $^{1,2}$ \\ (1) Department of Internal Medicine, Suwa Central Hospital, Chino, Nagano, Japan ; (2) Department of Obstetrics and Gynecology, Suwa Central Hospital, Chino, Nagano, \\ Japan ; (3) Department of Medical Education Studies, International Research Center for Medical Education, Graduate School of Medicine, The University of Tokyo, 7-3-1
} Hongo, Bunkyo-ku, Tokyo 113-0033, Japan.

\section{Question}

A 37-year-old woman presented to the hospital with a 3-day history of right upper quadrant pain (RUQP), which worsened with deep breathing. On examination, she had fever $\left(38^{\circ} \mathrm{C}\right)$ and RUQ tenderness. Laboratory tests showed white-cell count of $8.1 \times 10^{9} / \mathrm{L}$ and C-reactive protein level of $29.4 \mathrm{mg} / \mathrm{L}$. Liver profiles were within normal range (aspartate aminotransferase $20 \mathrm{U} / \mathrm{L}$ and alanine aminotransferase $22 \mathrm{U} / \mathrm{L}$ ). Immediately, contrastenhanced computed tomography (CECT) was performed (Figure 1). What is your diagnosis?

\section{Answer}

Arterial-phase CECT demonstrated increased perihepatic enhancement. Polymerase chain reaction testing of cervical discharge was positive for Chlamydia trachomatis. We made the diagnosis of Fitz-Hugh-Curtis Syndrome (FHCS). A thorough history-taking revealed that the patient had had unprotected sex with a partner. She completely recovered after azithromycin was administered.

FHCS is an acute perihepatitis as a rare complication of pelvic inflammatory disease (PID). Its main etiologic agents are Chlamydia trachomatis and Neisseria gonorrhoeae. FHCS is characterized by RUQP that is exacerbated by body movement and deep inspiration. Antibiotics with analgesics is the treatment of choice.

CECT has recently become a main diagnostic method for FHCS, while classical standard diagnosis requires invasive procedures such as laparoscopy and laparotomy $(1,2)$. Hepatic capsular enhancement on CECT is a typical finding of FHCS. The finding reflects increased blood flow at the inflamed hepatic capsule (3).

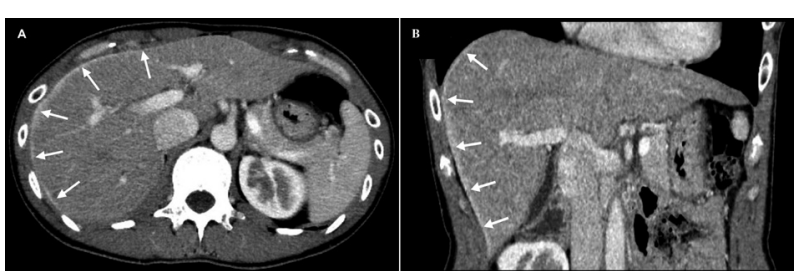

Figure 1. - Arterial-phase contrast-enhanced computed tomography demonstrated increased perihepatic enhancement (A, axial view ; $\mathrm{B}$, coronal view).

Because FHCS may present with isolated RUQP and no signs of PID, it can mimic other more common diseases including acute cholecystitis. Because FHCS can cause infertility and miscarriage, early diagnosis is crucial. Therefore, clinicians should consider FHCS as a possible differential diagnosis of RUQP in women and examine CECT.

\section{Competing interests}

None.

\section{References}

1. NISHIE A, YOSHIMITSU K, IRIE H, YOSHITAKE T, AIBE H, TAJIMA T, et al. Fitz-Hugh-Curtis syndrome. Radiologic manifestation. J. Comput. Assist. Tomogr., 2003, $27:$ 786-791.

2. VAN GOSSUM M, BURETTE A, JONAS C, NYST JF, DELTENRE M Périhépatite à Chlamydia trachomatis. Valeur diagnostique et thérapeutique de la laparoscopie [Perihepatitis due to Chlamydia trachomatis. The diagnostic and therapeutic value of laparoscopy]. Acta Gastroenterol. Belg. 1987, 50 : 445-449.

3. KIM JY, KIM Y, JEONG WK, SONG SY, CHO OK. Perihepatitis with pelvic inflammatory disease (PID) on MDCT: characteristic findings and relevance to PID. Abdom. Imaging, 2009, $34:$ : 737-742.

\footnotetext{
Correspondence to : Hirohisa Fujikawa, M.D., Department of Medical Education Studies, International Research Center for Medical Education, Graduate School of Medicine, The University of Tokyo, 7-3-1 Hongo, Bunkyo-ku, Tokyo 1130033, Japan. Phone : +81-3-5841-3480. Fax: +81-3-5841-0254

Email : hirohisa.fujikawa@gmail.com

Submission date : 10/11/2020

Acceptance date : 22/11/2020
} 